\title{
The impact of strategic planning practices on organizational performance in public sectors in Abu Dhabi
}

\author{
Mohammed Al Sudain \\ University of Dubai \\ E-mail: m555@live.com \\ Arunprasad P \\ E-mail: arun@ud.ac.ae \\ University of Dubai
}

\begin{abstract}
The growth of any economy is mutually dependent on public and private sectors contribution to the overall success, and can be directly attributed to the strategic planning and execution. The significant growth of UAE economy even during the global recession, is an indicator of robust strategic planning initiatives proposed and meticulously being executed by the respective emirates, in particular Dubai and Abu Dhabi share a greater contribution. Previous studies have mainly focused on the relation in strategic planning of company and performance in some of the global context specific to certain countries. With the onset of growing economic initiatives in UAE, with Abu Dhabi as Nation's capital, it is extremely important to study the importance of strategic planning and its significance in public sectors. This study attempts to conceptualize the factors determining the performance of Public sectors in Abu Dhabi from the perspective of strategic planning and practices. Strategic planning can share and develop the long-term perspectives. Public sector organizations are increasingly embracing the practices of strategic planning in anticipation that they will translate it to enhance the performances.
\end{abstract}

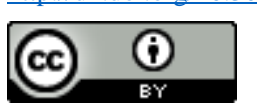

2523-6547 - Copyright: (C) 2017 The Authors. This is an open access article distributed under the terms of the Creative Commons Attribution License, which permits unrestricted use, distribution, and reproduction in any medium, provided the original author and source are credited. 


\section{Introduction}

In the past years, the localities constituting in the United Arab Emirates, have limited activities related with economy. Some of these localities are sparsely populated and are having low level of the physical and human development. Both in terms of infrastructure and education level (Nyarko, 2010). United Arab Emirates saw a paradigm shift after the discovery of the oil in the 1960s. More than 10 percent of the crude oil reserves are under the boundaries of the United Arab Emirates. With the rise in the economy level, the economy of the United Arab Emirates is considered as the main economic force with the help of sovereign funds. United Arab Emirates is known for having political stability and economic development with the strategies like increment in the oil revenues by staffing labors from west and low skilled workforce from Asia. In the past many years, the economic plan of United Arab Emirates is considered as free economic textbook. On the platform of international economic field, United Arab Emirates is considered as main player. UAE always remains in the news and the main sovereign wealth funds are kept in the connection with the stability of the currency. With the average annualized rate of 5.5 percent, the economy of the United Arab Emirates has been growing at an aggressive rate (Nyarko, 2010).

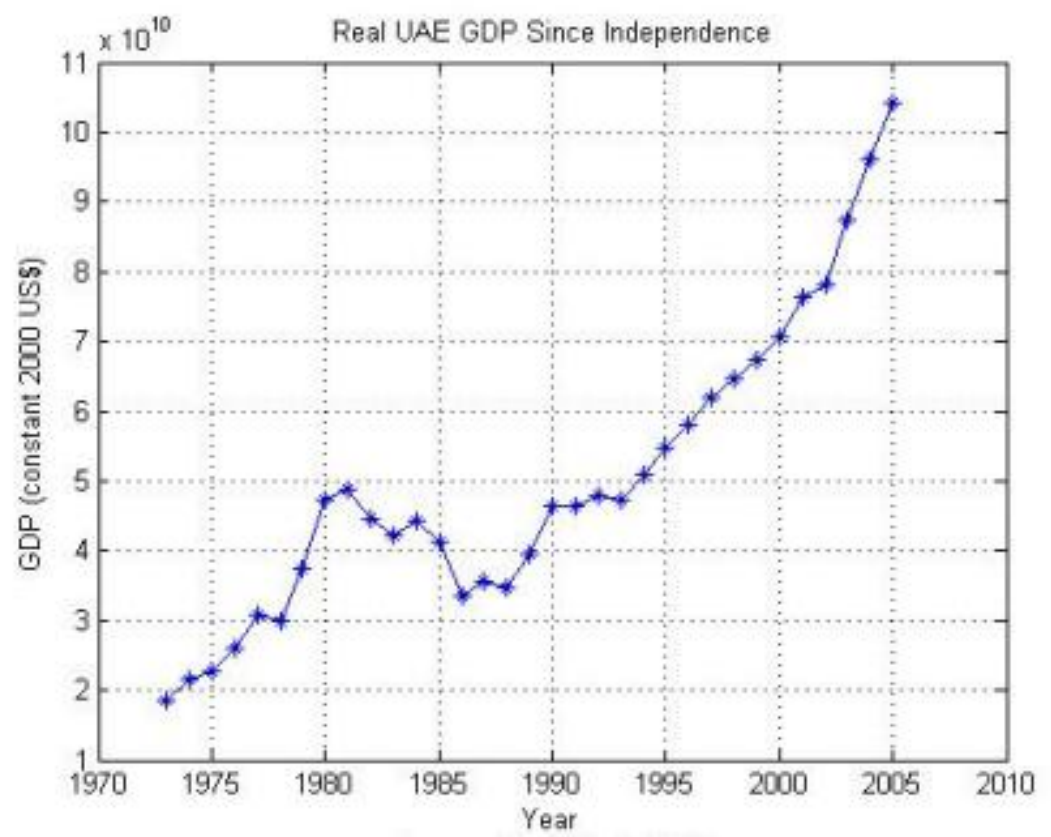

Figure 1: Real Gross Domestic product since independence (Nyarko, 2010)

Oil production is the main factor behind the development of economy of Abu Dhabi. Abu Dhabi accounts for 90 percent of the oil reserves of the United Arab Emirates. In addition, 90\% of oil production of UAE comes from Abu Dhabi. Considering production of 3 million barrels a day and oil price of 100 USD per barrel, revenue generated is around USD 90 billion per year. However, major part of the amount goes to foreign oil production partners and the rest part goes into repayment of debt amounts but still it gives rough estimate of revenues. Looking towards the production rates of oil reserves of the Abu Dhabi, it will not be wrong in saying that the reserves are going to last for hundred coming years (Shihab, 2002).

Oil is the main revenue source for the United Arab Emirates. However, for having more revenue sources, country is planning to diversify the segments of economy. According to the economic reviews, contribution made by oil and gas sector is around one third of Gross Domestic Product. The main economic strategy of Abu Dhabi has been associated with the sovereign wealth funds, possessing sizeable resource amount, are invested in the welldiversified portfolio structure, outside the country. The main sovereign wealth fund is the Abu Dhabi Investment Authority. This is mainly considered as one of the government funds, that makes the savings of the government invest in the currencies of other countries. Many projects have been announced by the government of United Arab Emirates for the creation and development of branches in Abu Dhabi of different cultures like, Contemporary Art in France. This has been done to have investment from other countries also. This is mainly the importation of the foreign skilled institutions in Abu Dhabi for the development of the country. This option is quite popular amongst the independent countries now days. This option calls for dynamism in the structure of countries (Nyarko, 2010).

2523-6547 - Copyright: (C) 2017 The Authors. This is an open access article distributed under the terms of the Creative Commons Attribution License, which permits unrestricted use, distribution, and reproduction in any medium, provided the original author and source are credited. 
Strategic planning is considered as critical to business success. Different from classic business planning, the strategic variety involves vision, mission and out of box thinking. Strategic planning defines where a company is heading. Now day's public companies in Abu Dhabi are facing issues like

- Public companies get confused with the operational plans, and they consider operational plan as strategic plans. On the other side, strategic planning functions as the design like the blue print functions for building something.

- Unlike the business plans, public companies are not able to make the right way for creating strategic planning.

- Public companies fail in setting directions and priorities

- The decision making process of public companies is cumbersome.

From all the above-discussed challenges, it can be easily determined that, strategic planning is important for public companies and, the public companies in Abu Dhabi are not able to determine the relationship in between strategic planning and performance of business.

The main issues faced by Abu Dhabi in the growth journey were related with the management of the economy recovery with emphasis on the findings of new sources of growth, monitoring of the competitive environment, management of strategic planning and adjusting the challenging changes due to continued globalization (Nyarko, 2010). The main debate is over the efficiency of strategic planning on the performance of an organization. Organizational performance has always been associated with strategic planning and it requires going deep in the strategic planning process by evaluating the operational execution, the effect on the overall performance of the staff and productivity of the employees that manifests with the financial and non-financial dimensions.

Strategic planning is related to positioning of the organization in a competitive environment to offer varied factors and practical guidance for improving the competitiveness and efficiency of the operations. In the times of turbulence, companies majorly take the perspective for developing the strategic plans. As, leadership involves organizing of the group of individuals for achieving the common goal, it is up to the leaders of the organization for establishing clear direction and implementing an appropriate business strategy for achieving the desired objectives (Falshaw, Glaister, \& Tatoglu, 2004).

\section{Objective of the Research Study}

The research study aims towards:

- Examining the relationship in between the strategic planning and the performance of organizations

- Evaluating the impact of the strategic planning on the planning outcomes

- Evaluating the impact of the planning outcomes on the performance of the organization

Indeed, the important issue in the research on the strategic process is whether the comprehensive fashion enables the companies in United Arab Emirates to make better decisions related with strategies and improving the performance of the varied environmental contexts. Strategic planning, companies' performance and measurement continue to be challenging because of the complexity in the terms of performance. The major research questions to be explained through the conceptual framework: How are strategic planning practices and effectiveness contribute to employee satisfaction, customer's satisfaction, social performance and environmental performance?

Research in respect of the relationship in between the strategic planning and the performance of a company, has enhanced since the empirical study done by (Elbanna \& Child, The Influence of Decision, Environmental and Firm Characteristics on the Rationality of Strategic Decision-Making, 2007). The study lead towards the findings of better economic performance for the business planners compared with the non-planners. In fact, the question concerns that the relationship in between planning and performance of the companies of Abu Dhabi has been subject of growing interest to the researchers. This leads many researchers to believe that impact of strategic planning on performance of the company is a critical issue. The report study done by Wheelen and Hunger, (Wheelen \& Hunger, 2011)shows that respondents in all the sectors are having positive attitude towards the strategic planning as a management tool. Senior management teams can lead towards building on the positive attitudes in order to entrench the strategic planning firmly in the organizations working in Abu Dhabi.

2523-6547 - Copyright: (C) 2017 The Authors. This is an open access article distributed under the terms of the Creative Commons Attribution License, which permits unrestricted use, distribution, and reproduction in any medium, provided the original author and source are credited. 


\section{Literature Review \\ Strategic Planning}

As per Wheelen \& Hunger (2011) over the time, the usage of strategic tools enhances the efficiency of the planning system itself. Strategic planning involves the creation of the detailed plans for implementing policies and strategies for achieving objectives and basic company purposes. On the same side, view planning is also conscious, systematic process during which, the decision-making is done regarding the goals and activities (Wheelen \& Hunger, 2011).

Santos \& Brito (2009) in their research reported that the participation from the management in the strategic planning influences the utilitarian consequences of planning and the psychological planning consequences. Elbanna \& Child (2007) suggests that the participation from senior management in the strategy development is essential for the better performance of an organization. Elbanna (2009) contends that strategic planning is about management by plans, an analytical processing and is focused in making optimal strategic decisions. Arasa \& K'Obonyo (2012) in their research conceptualize that strategic planning is the process, which seeks a better match in between a firm's product and technology. Strategic plan is considered as the technique for illustrating the mission of a company for developing the strategic plan to achieve the process of outlining the long-term vision for the company. The relationship in between the planning and the organizational outcomes is considered as one of the most extensively researched issue in the fields of the strategic management and it suggests that the managers in United Arab Emirates are likely to keep the long hierarchical distances.

\section{Strategic Planning and Strategic Effectiveness}

The empirical studies examine the relationship in between strategic planning and the performances, that falls in between supporters and opponents. In this particular context, the literature review in the research study aims for finding the impacts of the strategic planning on the non- financial organizational performances, which pays particular attention towards the concepts related with strategic planning like environmental scanning, formulation of strategy, control, evaluation and the contingency planning (Falshaw, Glaister, \& Tatoglu, 2004).

The Meta analysis by Jenster \& Søilen (2012) identified that strategic planning positively affects the firm's performance. As per Falshaw, Glaister, \& Tatoglu (2004), strategic planning is beneficial for the organizations and they also reported that strategic planning practice is mainly associated with the strategic planning effectiveness. Authors notes that the empirical research in the strategic planning system mainly focuses on two areas: the impact of the strategic planning on the performance of the company and the role of the strategic planning in the strategic decision-making. In the context of United Arab Emirates, during the last decade, big changes have taken place in United Arab Emirates, in relation with the practices of the strategic management and such changes deserved the attention of the researchers.

\section{Strategic planning and Organizational Performance}

Kumar (2015) illustrated that research on strategic planning has proliferated in the past two decades or so, little is known about the issue in context of the developing countries. Survey was done for collecting data from the business firms in the Emirates. Results of the study, shows that, prevalence of strategic planning in the companies in United Arab Emirates, is still in its infancy mode. Only 10 percent of the surveyed companies use strategic planning. Furthermore, some of the companies seem to have the poor understanding of the practices of the strategic planning, for instance, the strategic planning in some of the companies is restricted for having plans without any documentation. Although many companies in United Arab Emirates do document the plans, the majority of the companies fail in having specific and measurable objectives. The author recommended that companies in Emirates should take up strategic planning seriously (Ketokivi, 2004).

In the year 2007, the prime Minister of United Arab Emirates duplicated the experience of strategic planning of Dubai in the federal organization. In the year 2008, main achievements by the government of Abu Dhabi brought everyone together for the announcement of the strategic plans for the varied departments and institutions (Elbanna \& Child, 2007).

\section{Conceptual Framework}

The literature review indicates that every dimension of strategic planning contributes to the studies of firm's performance. In accordance with such relationships, this conceptual framework is proposed in order to investigate the relationship in between formulation, communication, and implementation and control, contingency and strategic planning competency.

As discussed above, the previous studies have determined the importance of strategic planning on organizational performance. For instance Falshaw, Glaister, \& Tatoglu, (2004) has proven that the relationship in between strategic planning and organizational performance is positive. Evidences from the previous research has 
revealed that there are other dimensions of strategic planning that have been identified to have positive relationships with the organizational performance:

- Firstly, the formulation of strategic planning. Formulation of strategic planning is one of the main frequently studied factors. Saylor (2008) has proved that formation of the planning has positive relationship with the organizational performance (Nabardi, 2009).

- Second is the tool of strategic planning, which is communication, is believed to be able to increase the efficiency and effectiveness of the organization planning. Kumar (2015) believes that employing tool of strategic planning would be able to achieve better performance. The implementation of strategic planning is also another factor, which is one of the most important parts in strategic planning process. It is suggested by Sosiawani, Ramli, Mustafa, \& Yusoff (2015) that a successful strategic planning can explain whether it has been implemented properly or not. Jenster \& Søilen (2012) proved that by implementing strategic planning properly, it would be able to assist the firms to achieve better performance. Authors have recommended lengthening the time horizons of strategic planning for gaining better performance.

- Another dimension of strategic planning is the control of planning and evaluation. There is need of controlling the strategic planning to have control on the impacts of the factors on the performance of the firm (Cosmos, 2012).

- Contingency plan and strategic planning competency are other factors, which affects the organizational performance and needs to be taken care of. If company possess a perfect contingency plan and has competent managers for developing and driving a shared understanding of long term visions which incorporates people's opinion and describes what organization needs to look like. Strategic planning competency is needed as it is the competency, which describes the long-term objectives, and the tactics needed to achieve them. (Path Finder, 2000)

- On the other side, the mediating factors influencing the strategic planning and organizational performance are practice and effectiveness (Falshaw, Glaister, \& Tatoglu, 2004). Practice and effectiveness makes process streamlined and helps a company in implementing policies and strategies effectively. This means, if the practice and effectiveness are aggressive in nature than performance of the company will improve (Elbanna, 2008).

Strategic planning

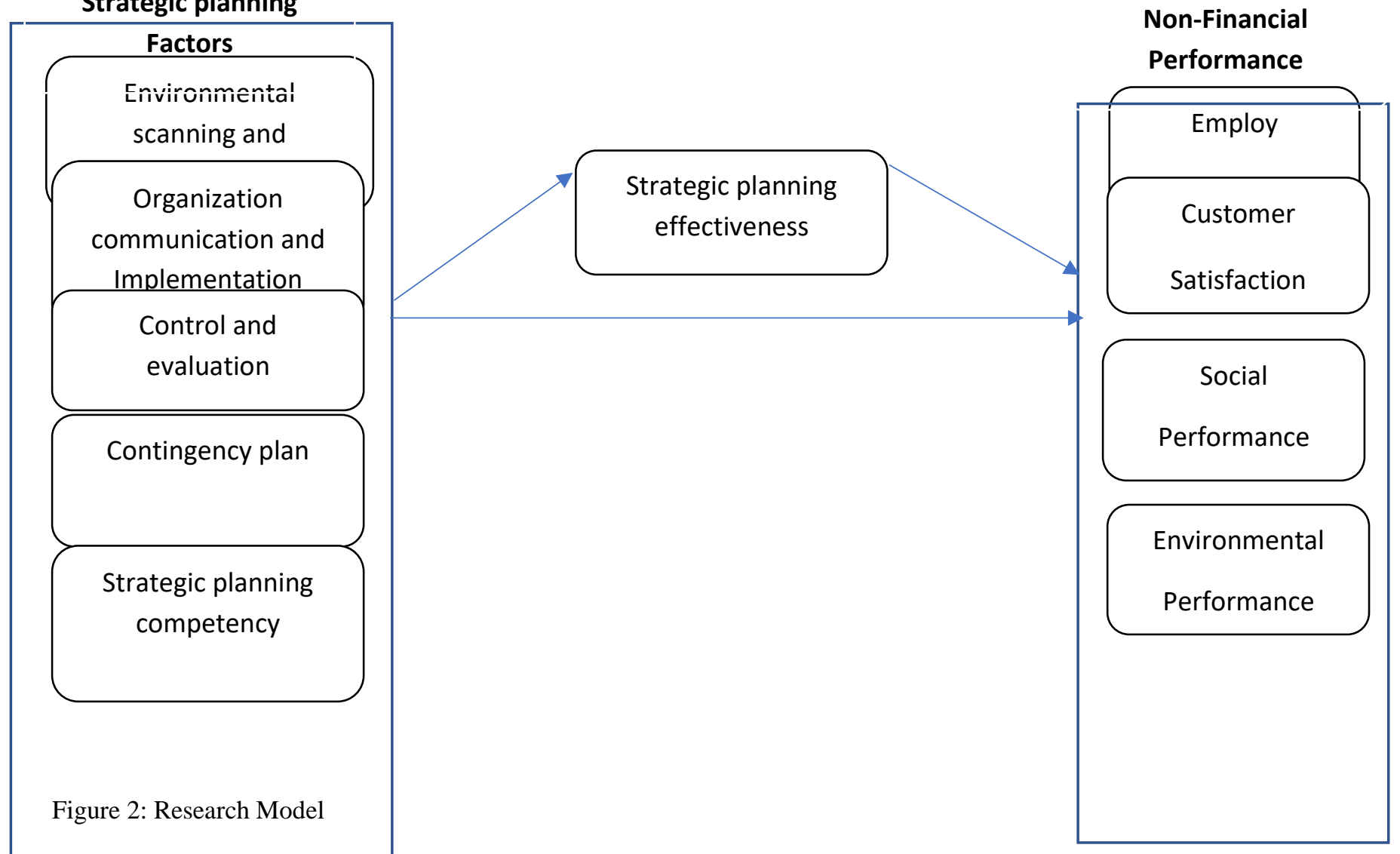

2523-6547 - Copyright: (C) 2017 The Authors. This is an open access article distributed under the terms of the Creative Commons Attribution License, which permits unrestricted use, distribution, and reproduction in any medium, provided the original author and source are credited. 


\section{Research Hypothesis}

In terms of non-financial performance, the previous studies have measured varied dimensions ranging from employee satisfaction to environment performance. While satisfaction of customer, employee satisfaction, social performance and environment performance are some of the aspects for measuring non-financial performance, but most important aspect is of practice and effectiveness behaving positively as mediator in between strategic planning and non- financial performances overall.

H1: There is a positive relationship between strategic planning and employee satisfaction

Sosiawani, Ramli, Mustafa, \& Yusoff (2015) believes that once strategic planning is implemented by an organization, they will be able to gain confidence of employees and above all, the employees will get satisfied from their job because of the strategic planning implementation. In this research study, we will be exploring the impact of strategic planning on employee satisfaction. The results analysis will reveal whether the outcomes of the study coincide with majority of the previous research done before or some new results are seen.

$\mathrm{H} 2$ : There is a positive relationship between strategic planning and customer satisfaction

The focus point is the satisfaction of the customers for every company. Strategic planning is considered as the systematic and less formalized effort for a company to establish the basic company purposes and strategies (Reis \& Peña, 2000). It involves the creation of the detailed analysis for implementing policies and achieving objectives related with customer satisfaction. So strategic planning is related with customer satisfaction and it is important to see what impact strategic planning creates on customer satisfaction (Pollock, 2000).

H3: There is a positive relationship between strategic planning and Social Performance

Now days having a social point of view of an organization is very necessary as, customers are now more aware and informed (Hatcher, 2008). So, it is necessary to know that implementation of strategic planning has what kind of impact on social performance of a company.

H4: There is a positive relationship between strategic planning and environmental performance

Strategic planning is internal activity whereas organization is generally influenced by external environment also. External environment is dynamic in nature and so, it is important to know what relationship strategic planning has with environmental performance (Dusenbury, 2000).

H5: Strategic planning effectiveness will positively mediate the relationship between strategic planning and nonfinancial performance

Strategic planning is a more or less formal implementation of policies and strategies in an organization that involves lots of practice and effectiveness. According to the previous studies (Wharton, 2000), researchers believe that if the organization possess aggressive practice and efficiency then, they are able to mediate well in between strategic planning and organizational performance. Hypothesis has been framed to identify the relationship in between strategic planning and non-financial performance (Wharton, 2000)

\section{Discussion}

The external and internal factors may have greater impact on the employee satisfaction. Internal environment affects the working environment and on the other side, the external factors affect the surrounding and overall satisfaction of the employees. Customers are given priority and their needs are accommodated properly for gaining their satisfaction. The study of Elbanna and co-author (Elbanna \& Child, The Influence of Decision, Environmental and Firm Characteristics on the Rationality of Strategic Decision-Making, 2007), determined that there is an association in between strategic planning and the performance of the company.

The question raised in the introduction part was about relationship in between strategic planning and organizational performance. The theoretical findings of this research study hypothesize that there could be a positive relationship between strategic planning and organizational performance. The organizational performance of a company gets positively impacted because of strategic planning, in terms of job satisfaction, customer satisfaction, social performance and environment performance. For instance, Elbanna (Elbanna S. , 2008), in his research identified that the companies implementing strategic planning in their work, are better planners in comparison to non-planners. The survey analysis done in the research study of Elbanna (Elbanna S. , 2008) shows that effectiveness and practice enhances the employee satisfaction and customer satisfaction of the organization. In respect of the non-financial performance, the prior studies have measured various dimensions, which range from employee satisfaction to environment performance. Satisfaction of the customer, employee satisfaction, social performance and environment performance are the aspects, which has been considered as the measurement of the non-financial performance. For instance, according to Sosiawani, Ramli, Mustafa and Yusoff research analysis, (Sosiawani, Ramli, Mustafa, \& Yusoff, 2015) shows that, if strategic planning is implemented than employees are able to gain information regarding the strategic objectives of a company and a clear guideline for their achievement. 
Strategic planning is a more or less formal implementation of policies and strategies in an organization that involves lots of practice and effectiveness. According to the previous researches (Wharton, 2000); researchers believe that if organization possess aggressive practice and efficiency, then they are able to mediate well in between strategic planning and organizational performance. Hypothesis has been framed to identify the relationship in between strategic planning and non-financial performance (Wharton, 2000)

Although many of the previous research offer the valuable knowledge in respect of strategic planning, there has been paucity of research that conceptualize and empirically measures the efficiency of the strategic planning. Moreover, the scarcity of the replication and the extensions in the literature of strategic management encourages the study to try to fill the gap.

\section{Conclusion}

The development of the strategic planning is the key step in the processing of management of the performance of the organization. As the examination of the impact of the strategic planning on the company's performance, attempts for finding possible links in between strategic planning as the independent variables and the performance of company as dependent variable. Approaches of senior management pay great attention to the achievement of the high profits. It works well for the minimization of the risk factors associated with the turbulent environment.

The study has some managerial implications, especially for the top management teams in Abu Dhabi, United Arab Emirates. They should strongly support the facts that an organization, which employs the tools of strategic planning, exhibits the enhanced effectiveness in the strategic planning. Thus, it seems warranted to recommend the usage of appropriate set of strategic planning tools as important elements in the organizational success. 


\section{Bibliography}

- $\quad$ Arasa, R., \& K'Obonyo, P. (2012). The Relationship between Strategic Planning and Firm Performance. International Journal of Humanities and Social Science .

- Bunning, C. (1992). Effective Strategic Planning in the Public Sector: Some Learnings. International Journal of Public Sector Management.

- Elbanna, S. (2008). "Planning and participation as determinants of strategic planning effectiveness: evidence from the Arabic context". Management Decision.

- Elbanna, S. (2009). Deter planning effectiveness: extension of earlier workminants of strategic. Journal of Strategy and Management.

- Elbanna, S., \& Child, J. (2007). The Influence of Decision, Environmental and Firm Characteristics on the Rationality of Strategic Decision-Making. Journal of Management Studies.

- Falshaw, J. R., Glaister, K. W., \& Tatoglu, E. (2004). Evidence on formal strategic planning and company performance. Journal of Management History.

- Jenster, P., \& Søilen, K. S. (2012). The Relationship between Strategic Planning and Company Performance - A Chinese perspective. Journal of Intelligence Studies in Business .

- Ketokivi, M. a. (2004). “Strategic planning as an integrative device”. Administrative Science Quarterly.

- $\quad$ Kumar, D. P. (2015). Correlation Between Strategic Planning and Firm Performance. IJMBS.

- $\quad$ Lines, R. (2004). "Influence of participation in strategic change: resistance, organizational commitment and change goal achievement". Journal of Change Management.

- $\quad$ Nyarko, Y. (2010). The United Arab Emirates. UNU.

- $\quad$ Rigby, D. K. (2013). MANAGEMENT TOOLS An executive's guide. Bain And Company.

- $\quad$ Santos, J. B., \& Brito, L. A. (2009). Toward a Measurement Model for Firm Performance. Anpad.

- Shihab, M. (2002). Economic Development in the UAE. UAE Interact.

- Wheelen, L. T., \& Hunger, J. D. (2011). Concepts in Strategic Management and Business Policy. Pearson Education. 
